\title{
A new antibiotic with potent activity targets MscL
}

\author{
Irene Iscla ${ }^{1}$, Robin Wray ${ }^{1}$, Paul Blount ${ }^{1}$, Jonah Larkins-Ford ${ }^{2}$, Annie L Conery ${ }^{2}$, Frederick M Ausubel ${ }^{2}$, \\ Soumya Ramu ${ }^{3}$, Angela Kavanagh ${ }^{3}$, Johnny X Huang ${ }^{3}$, Mark A Blaskovich ${ }^{3}$, Matthew A Cooper ${ }^{3}$, \\ Andres Obregon-Henao ${ }^{4}$, Ian Orme ${ }^{4}$, Edwin S Tjandra ${ }^{5}$, Uwe H Stroeher ${ }^{6}$, Melissa H Brown ${ }^{6}$, \\ Cindy Macardle ${ }^{7}$, Nick van Holst ${ }^{7}$, Chee Ling Tong ${ }^{8}$, Ashley D Slattery ${ }^{8}$, Christopher T Gibson ${ }^{8}$, \\ Colin L Raston ${ }^{8}$ and Ramiz A Boulos ${ }^{8}$
}

The growing problem of antibiotic-resistant bacteria is a major threat to human health. Paradoxically, new antibiotic discovery is declining, with most of the recently approved antibiotics corresponding to new uses for old antibiotics or structurally similar derivatives of known antibiotics. We used an in silico approach to design a new class of nontoxic antimicrobials for the bacteria-specific mechanosensitive ion channel of large conductance, MscL. One antimicrobial of this class, compound 10, is effective against methicillin-resistant Staphylococcus aureus with no cytotoxicity in human cell lines at the therapeutic concentrations. As predicted from in silico modeling, we show that the mechanism of action of compound 10 is at least partly dependent on interactions with MscL. Moreover we show that compound 10 cured a methicillin-resistant $S$. aureus infection in the model nematode Caenorhabditis elegans. Our work shows that compound 10, and other drugs that target MscL, are potentially important therapeutics against antibiotic-resistant bacterial infections.

The Journal of Antibiotics (2015) 68, 453-462; doi:10.1038/ja.2015.4; published online 4 February 2015

\section{INTRODUCTION}

The overprescription of antibiotics and failure of patients to complete antibiotic treatment regimens have contributed to the emergence of bacterial multi-drug resistance (MDR). At the same time, the large costs involved in developing new drugs, exacerbated by a complicated drug approval and patent process, ${ }^{1}$ have caused a dearth in new antibiotic research with many pharmaceutical companies choosing to focus their efforts on more profitable, higher volume drugs. ${ }^{2,3}$ As a result, fighting MDR bacterial infections in patients is becoming increasingly difficult with treatment options becoming very limited. ${ }^{4,5}$ Furthermore, there are relatively few novel small molecules in the antibiotic development pipeline. ${ }^{6}$

The mechanosensitive ion channel of large conductance (MscL) in bacteria is an attractive target for drug discovery because of its high level of conservation in bacterial species, and its absence from the human genome. Such level of conservation suggests that the channel has an important and conserved function, which has recently been highlighted as one of the top 20 targets for drug development. ${ }^{7}$ In Escherichia coli, the transmembrane MscL channel consists of five identical subunits, each composed of 136 amino acids. ${ }^{89}$ MscL has the largest pore size of any gated ion channel, estimated to be $28 \AA$ when fully open. ${ }^{10,11}$ Mechanosensitive channels have evolved to sense mechanical tension on the membrane and convert it into an electrochemical response. As such, they act as gatekeepers, protecting bacterial cells against lysis following acute decrease in the osmotic environment. Moreover, these channels can act as entry points for drugs and other small molecules into bacterial cells.

In this paper, we describe the in silico design of MscL ligands, which led to the discovery of a novel class of compounds with optimal binding to MscL. One of these ligands, 1,3,5-tris[(1E)-2'-(4"-benzoic acid)vinyl]benzene (referred to hereafter as 10, Ramizol), is an effective antimicrobial against methicillin-resistant Staphylococcus aureus (MRSA). ${ }^{12}$ Using microscopic analysis and other techniques, we show that the mechanism of action of $\mathbf{1 0}$ in Gram-positive and Gramnegative bacteria involves its interaction with MscL. We also show that 10 exhibits in vivo efficacy in a Caenorhabditis elegans nematode infection model. Moreover, 10 exhibits low levels of toxicity in addition to being a potent antioxidant, ${ }^{13}$ potentially providing an additional benefit by reducing bacterial-induced inflammation.

\section{RESULTS}

In silico design of ligands targeting MscL

To explore the potential of MscL as a target for antibiotics, we developed a spatial map between the exposed oxygen atoms of amino acids, lining the gate of the MscL channel. This three-dimensional spatial map was used for the de novo design ${ }^{14}$ of several potential

${ }^{1}$ Department of Physiology, UT Southwestern Med Ctr, Dallas, TX, USA; ${ }^{2}$ Department of Molecular Biology, Massachusetts General Hospital, Boston, MA, USA; ${ }^{3}$ Institute for Molecular Bioscience, University of Queensland, St Lucia, QLD, Australia; ${ }^{4}$ Department of Microbiology, Immunology, and Pathology, Colorado State University, Fort Collins, CO, USA; ${ }^{5}$ School of Animal Biology, The University of Western Australia, Crawley, WA, Australia; ${ }^{6}$ School of Biological Sciences, Flinders University, Bedford Park, SA, Australia; ${ }^{7}$ Flinders Medical Science and Technology, Immunology, Allergy and Arthritis, Flinders University, Bedford Park, SA, Australia and ${ }^{8}$ Centre for NanoScale Science and Technology, School of Chemical and Physical Sciences, Flinders University, Bedford Park, SA, Australia

Correspondence: Paul Blount or Dr R Boulos, Centre for NanoScale Science and Technology, School of Chemical and Physical Sciences, Flinders University, Bedford Park, South Australia 5042, Australia.

E-mail: Paul.blount@UTSouthwestern.edu or ramiz.boulos@flinders.edu.au

Received 19 September 2014; revised 27 November 2014; accepted 15 December 2014; published online 4 February 2015 
ligands capable of hydrogen bonding to the MscL channel amino acids as shown in Figure 1a. We calculated that one of these potential ligands, 1,2,4-tris[2'-(4"'-phenol)ethyl]benzene (ligand 2), had the lowest docking energy (Figure 1b). We then further optimized the binding of ligand 2 using iterative in silico docking models to identify related structures with lower docking energies (Figure 1c). Specifically, the hydroxyl groups in ligand 2 were substituted with a variety of functional groups (aldehydes, amide cations, amino, carboxyl, chloride). With reference to Figure $1 c$, we found that the addition of carboxyl groups to the 'b', 'c' and 'd' positions resulted in the most favorable docking energies. This ligand, 8 , was determined to have a free energy of binding equivalent to $\sim-55.94 \mathrm{~kJ} \mathrm{~mol}^{-1}$, which is higher than previously screened candidates from the National Cancer Institute database. Thus, compound 8 and its analogs represent a potentially novel class of antimicrobials based on p-carboethoxytristyryl and $p$-carboethoxy-terastyrenyl benzene derivatives.

\section{Compound 10 is a potent antibiotic against a range of Gram- positive bacteria}

We further investigated a particular analog of compound 8: the symmetrical and fluorescent molecule $\mathbf{1 0}$, which, based on preliminary disk diffusion studies, was found to be more effective than the other analogs ${ }^{12}$ with the exception of $2,2^{\prime}, 2^{\prime \prime}-\left\{\left[\left(1 E, 1^{\prime} E, 1^{\prime \prime} E\right)\right.\right.$-benzene1,3,5-triyltris(ethene-2,1-diyl)] tris(benzene-4,1-diyl)\}triacetic acid, 11 which was only discovered recently. ${ }^{15}$ As shown in Table 1,10 is a potent antimicrobial against a variety of $S$. aureus strains with minimum ICs (MICs) of $\sim 4 \mu \mathrm{g} \mathrm{ml}^{-1}$. These $S$. aureus strains include a variety of drug-resistant MRSA, glycopeptide intermediate $S$. aureus (GISA) and vancomycin-resistant $S$. aureus (VRSA) strains, including a MRSA strain that is daptomycin-resistant. 10 was also effective against an MDR Streptococcus pneumoniae strain with a MIC of $4 \mu \mathrm{g} \mathrm{ml}^{-1}$. In contrast, 10 was relatively inactive (MIC $>64 \mu \mathrm{g} \mathrm{ml}^{-1}$ ) against Enterococcus faecalis VanA clinical isolate and E. faecium MDR-VanA ATCC 51559. 10 was also inactive against a variety of Gram-negative bacteria tested (E. coli ATCC 25922, Klebsiella pneumoniae ATCC 700603, K. pneumoniae ATCC 13883, Acinetobacter baumannii ATCC 19606 and Pseudomonas aeruginosa ATCC 27853) with an MIC>64$\mu \mathrm{g} \mathrm{ml}^{-1}$ (data not shown), but showed marginal activity against a $P$. aeruginosa polymyxin-resistant strain (MIC $64 \mu \mathrm{g} \mathrm{ml}^{-1}$ ) and a K. pneumoniae BAA-2146 NDM-1-positive strain (MIC $64 \mu \mathrm{g} \mathrm{ml}^{-1}$ ).

Compound $\mathbf{1 0}$ also showed no significant activity against M. tuberculosis strains $\mathrm{H} 37 \mathrm{Rv}$ and TT372 grown in $7 \mathrm{H} 9$ medium (MIC $160 \mu \mathrm{g} \mathrm{ml}^{-1}$ ). However, when H37Rv was grown in Proskauer and Beck medium or in glycerol-alanine-salts media, the MIC was $20 \mu \mathrm{g} \mathrm{ml}^{-1}$ (Table 1). One possible explanation for this observation is that the $7 \mathrm{H} 9$ medium contains albumin. It is well established that high affinity of albumin to a wide range of structurally different drugs ${ }^{16}$ can affect their bioavailability. If $\mathbf{1 0}$ does indeed bind to albumin,

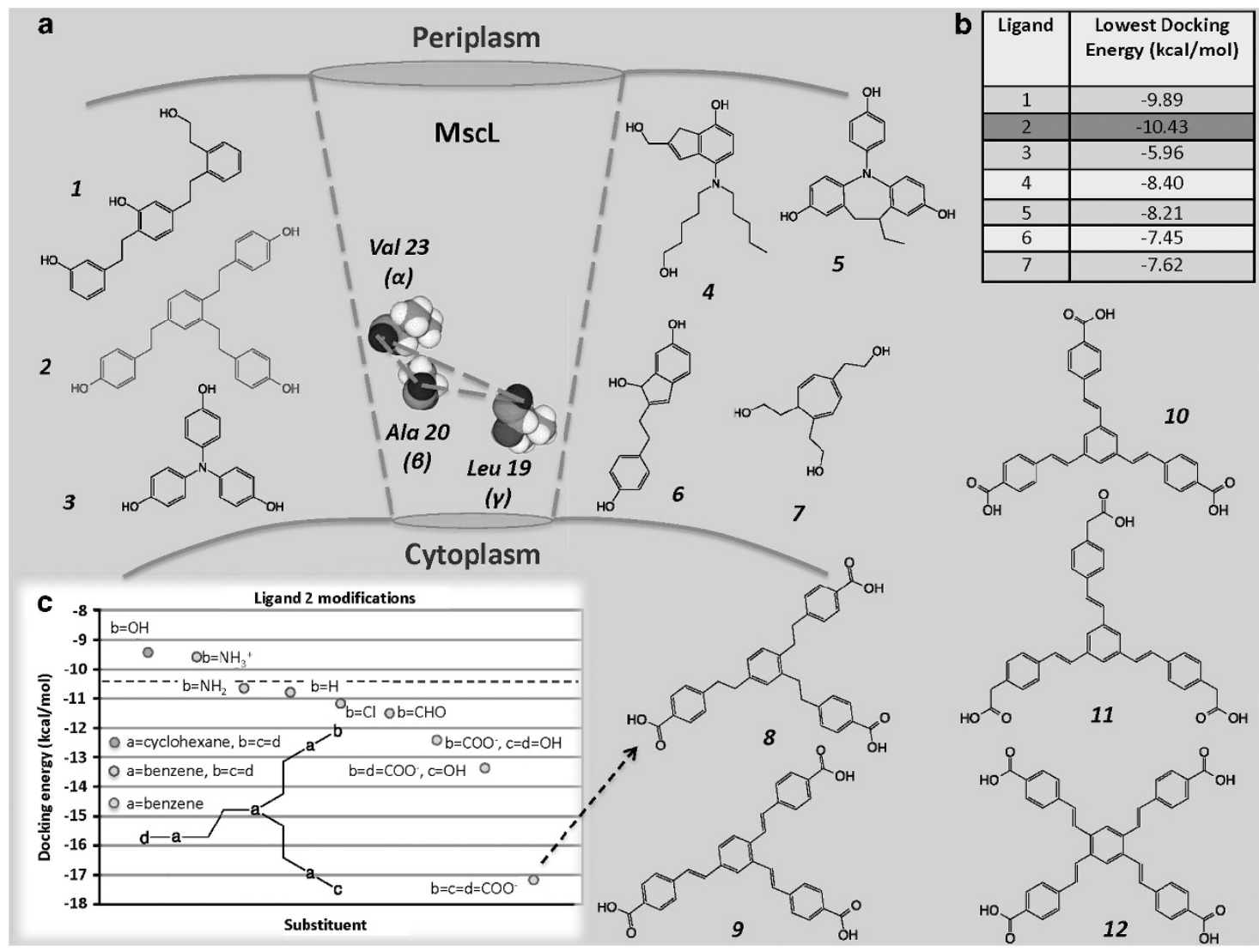

Figure 1 (a) Diagrammatic representation of target amino acids Leu19, Ala20 and Val23 in close proximity to the E. coli MscL channel gate, which were used for the de novo design of the designated ligands. (b) Docking energies (kcal mol-1) of the ligands. (c) Iterative in silico docking of lead ligand 2 , which gave rise to new class of antimicrobials including compounds 8-12. A full color version of this figure is available at The Journal of Antibiotics journal online. 
Table 1 MIC data of antibiotics ( $\mu \mathrm{g} \mathrm{ml}^{-1}$ ) against drug-resistant bacterial strains

\begin{tabular}{|c|c|c|c|c|c|c|}
\hline Compound & $\begin{array}{l}\text { S. aureus MRSA } \\
\text { clinical isolate }\end{array}$ & $\begin{array}{l}\text { S. aureus MRSA } \\
\text { ATCC } 43300\end{array}$ & $\begin{array}{c}\text { S. aureus GISA } \\
\text { NRS } 17\end{array}$ & $\begin{array}{c}\text { S. aureus MRSA DapRSA } \\
\text { clinical isolate }\end{array}$ & $\begin{array}{c}\text { S. aureus GISA, MRSA } \\
\text { NRS } 1\end{array}$ & $\begin{array}{c}\text { S. pneum MDR ATCC } \\
700677\end{array}$ \\
\hline Vancomycin & 1 & 1 & 4 & 2 & 4 & 1 \\
\hline Compound & \multicolumn{2}{|c|}{ S. aureus NARSA VRS $3 b$} & S. aureus NARSA VRS 4 & \multicolumn{2}{|c|}{ S. aureus NARSA VRS 1} & S. aureus NARSA VRS 10 \\
\hline Daptomycin & \multicolumn{2}{|c|}{1} & 2 & \multicolumn{2}{|c|}{4} & 4 \\
\hline Dalbavancin & \multicolumn{2}{|c|}{1} & 16 & \multicolumn{2}{|c|}{$>64$} & $>64$ \\
\hline Telavancin & \multicolumn{2}{|c|}{0.5} & 1 & \multicolumn{2}{|c|}{2} & 4 \\
\hline Compound 10 & \multicolumn{2}{|c|}{4} & 4 & \multicolumn{2}{|c|}{4} & 4 \\
\hline
\end{tabular}

M. tuberculosis $H 37 R V$

\begin{tabular}{lccc} 
Compound & GAS medium & P\&B medium & 7H9 medium \\
\hline Rifampicin & $<0.002$ & $<0.002$ & $<40$ \\
Compound 10 & 20 & 20 & 160 \\
\hline
\end{tabular}

Abbreviations: GAS, glycerol-alanine-salts; GISA, glycopeptide intermediate S. aureus; MDR, multi-drug resistant; MIC, minimum inhibitory concentration; MRSA, methicillin-resistant Staphylococcus aureus; NARSA, Network of Antimicrobial Resistance in S. aureus; P\&B, Proskauer and Beck; VRS, vancomycin-resistant S. aureus. Comparison of efficacy of 10 and vancomycin against a panel of MRSA and glycopeptide intermediate $S$. aureus, and MDR S. pneumonia, comparison of efficacy of 10 and commercial antibiotics against a panel of vancomycin-resistant $S$. aureus from the

Network of Antimicrobial Resistance in S. aureus, and comparison of efficacy of 10 and rifampicin against MDR Mycobacterium tuberculosis H37RV and TT372 strains. The 7H9 medium contains oleic acid, albumin, dextrose and catalase, which is needed for the growth of the bacteria. GAS medium has a final pH of 6.6 and the Proskauer and Beck (P\&B) medium has a final $\mathrm{pH}$ of 7.4 . A full color version of this table is available at The Journal of Antibiotics journal online.

it suggests that the structure of $\mathbf{1 0}$ may be further optimized to increase its bioavailability. For a detailed chart, see Supplementary Figure S1.

\section{Compound 10 toxicity}

We measured the cytotoxicity of $\mathbf{1 0}$ against a number of human tissue culture cell lines. The growth of NIH/3T3 and HaCaT cells was not affected by $50 \mu \mathrm{g} \mathrm{ml}^{-1}$ of 10 , and at $100 \mu \mathrm{g} \mathrm{ml}^{-1}$ only a marginal effect on growth was observed, whereas $500 \mathrm{\mu g} \mathrm{ml}^{-1}$ of 10 completely blocked the growth of these cells (Supplementary Figures S2a and b). Testing for $24 \mathrm{~h}$ on other cell lines such as HepG2 and HEK293 revealed no cytotoxicity up to $50 \mu \mathrm{g} \mathrm{ml}^{-1}$ of $\mathbf{1 0}$ (Supplementary Figures S2c and d). Therefore toxicity to eukaryotic cells is not seen until $\sim 10$ times the MIC against $S$. aureus.

\section{Compound 10 acts through $\mathrm{MscL}$}

As 10 was specifically designed as a ligand for MscL, we sought evidence that the antimicrobial activity of $\mathbf{1 0}$ is a consequence of its interaction with the MscL channel. Even though $\mathbf{1 0}$ is not as effective against some Gram-negative species and strains, we reasoned that if the particular parental E. coli strain (FRAG-1) that was used to generate all of the mechanosensitive channel null strains was sensitive enough to 10 , we should be able to determine whether the potency of 10 is dependant on MscL. We therefore tested these strains. In addition, a variety of genetic and physiological tools are readily available in E. coli for the analysis of mechanosensitive channels making it the organism of choice for such experiments.

Growth inhibition assays of $\mathbf{1 0}$ were performed using E. coli MJF612 ${ }^{17}$ carrying an empty vector, expressing wild-type E. coli MscL (Eco MscL), expressing a MscL K55T mutant that is slightly more sensitive to tension, ${ }^{9}$ expressing the MscL orthologues from Clostridium perfingens ( $\mathrm{CP} \mathrm{MscL}$ ), or expressing the MscL orthologue from S. aureus (SA MscL). For concentrations of 10 in the $7.5-10 \mu \mathrm{g} \mathrm{ml}^{-1}$ range, all strains expressing $m s c L$ except the $m s c L$ homolog from S. aureus showed reduced growth in a pilot-experiment titration curve compared with the control strain carrying the empty vector (Figure 2a). These data suggest that at concentrations of $\sim 7.5 \mu \mathrm{g} \mathrm{ml}^{-1}$, $\mathrm{MscL}$ is required for the mediated growth inhibition of $\mathbf{1 0}$. In contrast, at $\sim 16.5 \mu \mathrm{g} \mathrm{ml}^{-1}$, all strains were equally inhibited, suggesting that MscL is not the only target of $\mathbf{1 0}$ at concentrations greater than this concentration.

In a separate experiment, E. coli MJF612 expressing various mscL genes was grown to stationary phase in the presence of $13.5 \mu \mathrm{g} \mathrm{ml}^{-1}$ of 10. E. coli MJF612 expressing the unrelated E. coli mechanosensitive channel of small conductance ( $\mathrm{MscS})$, which also detects membrane tension, was included to examine whether $\mathbf{1 0}$ has specificity for MscL. Cells expressing Eco MscL, Eco K55T MscL and C. perfringens MscL showed a decreased growth dependant on 10, whereas cells containing an empty vector and those expressing SA MscL showed growth independent of 10 (Figure 2b). Bacteria expressing MscS were also sensitive to 10 , however the decrease in growth rate observed for the E. coli expressing MscS was only half of the strain expressing MscL. The observation that expression of SA MscL in E. coli does not confer sensitivity to $\mathbf{1 0}$ may not be surprising given that SA MscL is more difficult to gate when in E. coli membrane compared with being in its native membranes. ${ }^{18}$ This is possibly due to the requirement of $S$. aureus endogenous lipid composition much like for the M. tuberculosis MscL. ${ }^{19}$ These data show that MscL, and to a lesser extent MscS expression, affect the efficacy of the drug.

To determine whether $\mathbf{1 0}$ directly affects the activity of the MscL channel, we carried out patch-clamp experiments of native membranes using an E. coli 'giant' spheroplast preparation derived from strain PB104 (an mscL null mutant in which Eco MscL is overexpressed to enhance the number of channel activities observed ${ }^{20}$ ). The response of MscL to pressure across the patch was assessed before and after treatment with $25 \mu \mathrm{g} \mathrm{ml}^{-1}$ of $\mathbf{1 0}$. As shown in Figure $2 \mathrm{c}$, 
a

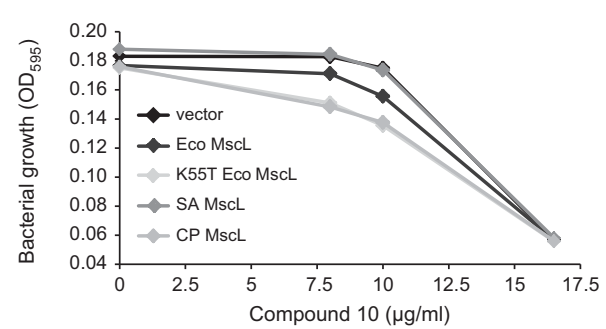

b

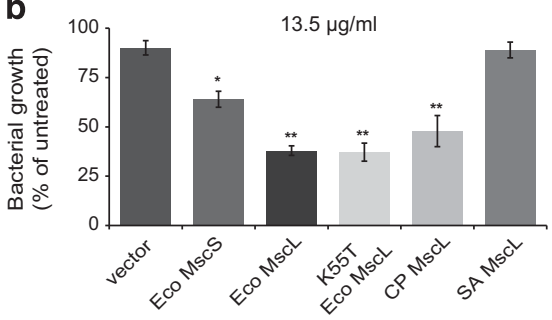

C

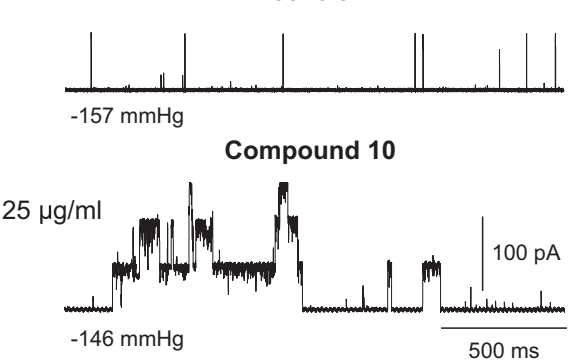

d
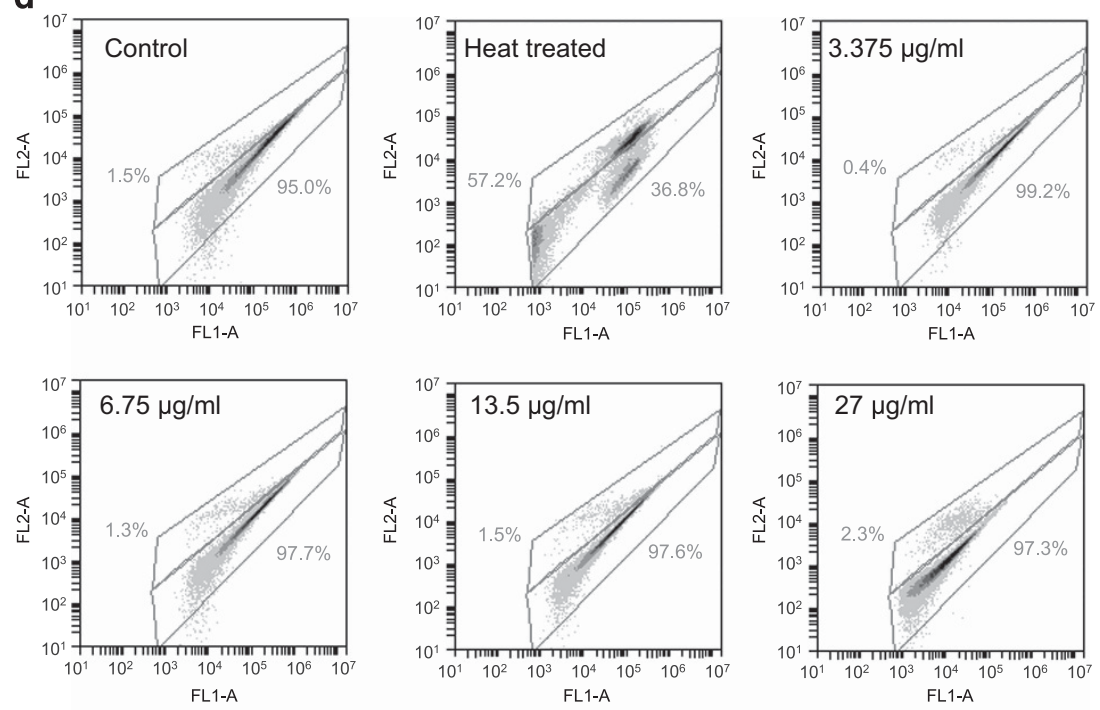

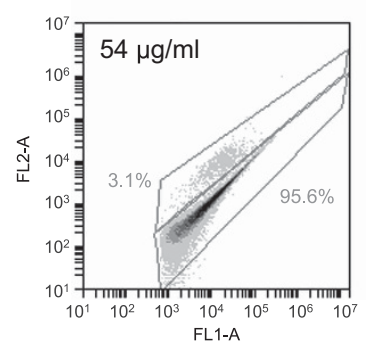

Figure 2 Mechanism of action studies. (a) Titration curve showing the effect of different concentrations of 10 on growth of E. coli MJF612 bacteria carrying an empty vector (dark blue) or expressing E. coli (Eco) MscL (red), K55T Eco MscL (green), S. aureus (SA) MscL (light blue) or C. perfingens (CP) MscL (orange). Note that the SA MscL data directly overlay the data for the vector-only-negative control. Each OD point presented is the average of four wells and all experiments are internally controlled. (b) The growth of cultures at stationary phase with or without at $13.5 \mu \mathrm{gl}$-of 10 was measured for MJF612 bacteria carrying an empty vector (dark blue) or expressing Eco MscS (purple), Eco MscL (red), K55T Eco MscL (green), SA MscL (light blue) or CP MscL (orange). Bacterial growth is represented as a percentage of the untreated samples. ${ }^{*} P \leqslant 0.0045,{ }^{*} P \leqslant 0.0001$, One-way ANOVA and Dunnett's multiple comparison test against empty vector. (c) Effect of 10 on MscL channel activity in native bacterial membranes. MscL channel activity was measured before (top) and after the addition of $25 \mathrm{\mu g} \mathrm{ml}^{-1}$ of 10 to the bath (bottom). Channels were activated by negative pressure applied to the patch. The traces are from the same patch held at the pressures shown for each trace (bottom left). (d) Flow cytometry data of $E$. coli (FRAG-1) untreated, heat-treated at $60^{\circ} \mathrm{C}$ for 20 min and treated with 10 at the designated concentrations. SYBR Green I was used as a DNA-staining agent and propidium iodide was used to detect membrane porosity. A full color version of this figure is available at The Journal of Antibiotics journal online.

characteristic MscL channel activities were easily seen, and a significant increase in the probability of channel opening was observed after treatment with 10. A decrease in the pressure threshold needed to gate Eco MscL was also observed after $10 \mathrm{~min}$ incubation with $\mathbf{1 0}$ $(82.9 \pm 4.3$ percentage of the pressure required to gate the untreated, $n=5, P \leqslant 0.02$, Student $t$-test paired). No change in the pressure threshold required to gate $\mathrm{MscS}$ was observed in these patch-clamp experiments $(97.7 \pm 4.9$ percentage of untreated, $n=4)$. As previously observed, such subtle increases in mechanosensitivity of MscL mutants in patch-clamp experiments can lead to significantly slower bacterial growth of strains harboring these mutants. ${ }^{9,21}$

To rule out the possibility that $\mathbf{1 0}$ simply disrupts bacterial cellular membranes at the concentration at which it is effective in the E. coli growth experiments (shown in Figure $2 \mathrm{a}$, Figure $2 \mathrm{~b}$ and the patchclamp results shown in Figure 2c), we carried out flow cytometry experiments in which E. coli FRAG-1 expressing Eco MscL treated with 10 were stained with propidium iodide (PI) (to test for the intactness of membranes) and SYBR Green I to stain all the cells. These flow cytometry data revealed that the control sample had $\sim 98.5 \%$ viability, as determined by the intensity of PI-stained cells (Figure 2d). As a control, cells were heated to $60^{\circ} \mathrm{C}$ for $20 \mathrm{~min}$, which resulted in $\sim 57 \%$ of the cells being permeable to PI. As shown in Figure $2 \mathrm{~d}$, the integrity of the E. coli FRAG-1 membranes was not compromised with concentrations of 10 up to $\sim 54 \mu \mathrm{g} \mathrm{ml}^{-1}$. However, there was an almost 100 -fold decrease in the intensity of the SYBR Green I as the concentration of 10 increased from $\sim 3.4$ to $54 \mu \mathrm{g} \mathrm{ml}^{-1}$, suggesting a significant decrease in DNA content as a result of inhibition of growth and cell division.

\section{Compound 10 causes morphological changes in S. aureus}

On the basis of the observations from the patch-clamp experiments and the titration experiments above, we hypothesized that the opening of the MscL channel caused by $\mathbf{1 0}$ might result in changes in the size and shape of bacterial cells. Low-magnification scanning electron microscopy (SEM) of S. aureus ATCC 6538 showed a decrease in bacterial density and biofilm formation, concurrent with an increase in the concentration of $\mathbf{1 0}$ (Supplementary Figure S3). Bacterial size measurements revealed that bacteria treated 
a
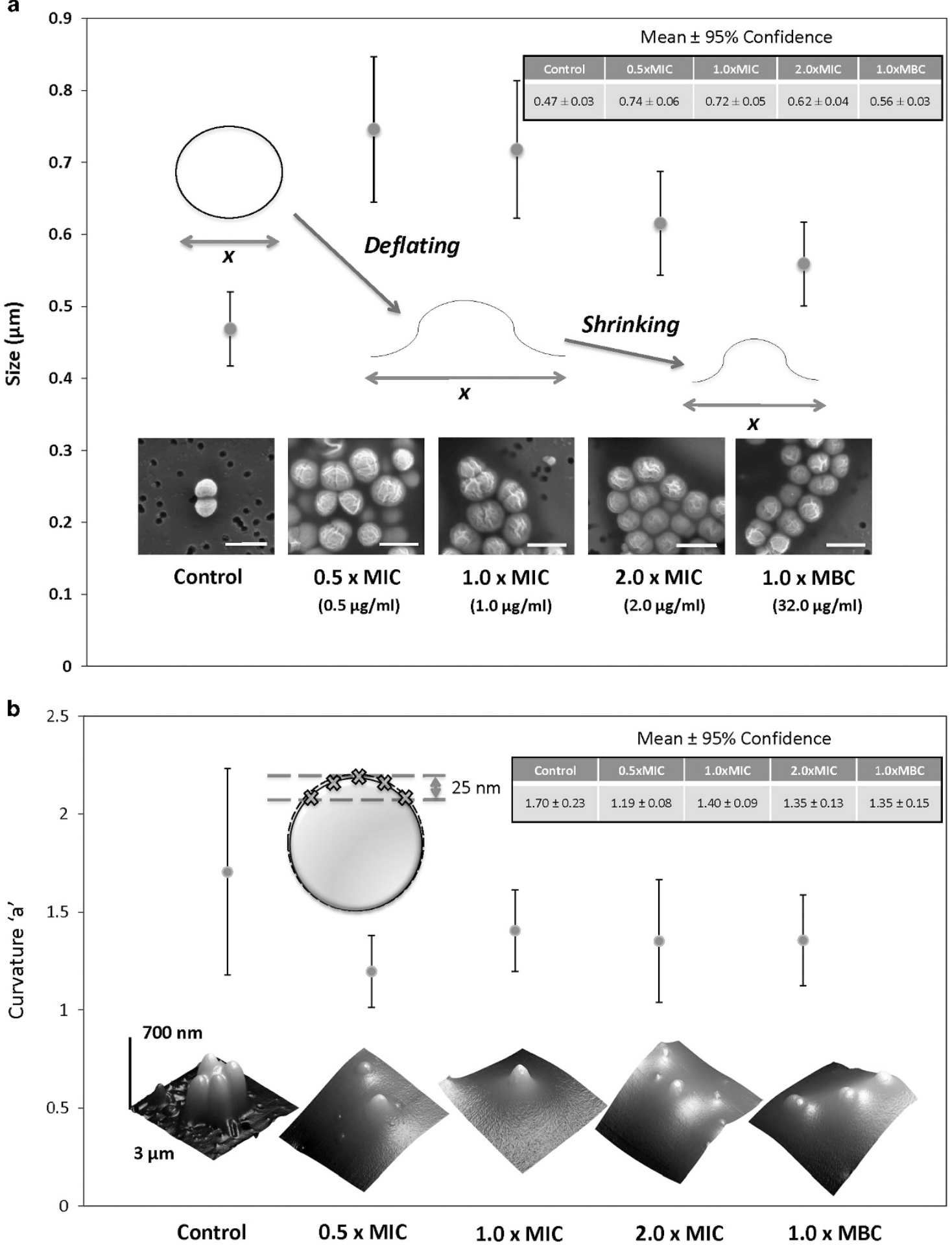

Figure 3 Microscopic analysis of S. aureus ATCC 29213 treated with 10 at different concentrations. (a) SEM images and size measurements of S. aureus with an inset showing the mean $\pm 95 \%$ confidence $(n=12)$. Scale bar $1 \mu \mathrm{m}$ and magnification $\sim 85000$. (b) The change in the 'a' parameter (representing bacteria curvature) is shown with representative 3D AFM images beneath $(3 \mu \mathrm{m} \times 3 \mu \mathrm{m} \times 700 \mathrm{~nm})$. The top $25 \mathrm{~nm}$ of an AFM scan was used as a basis for a parabolic equation fit $y=a x^{2}+b x+c$ to show the change in curvature after treatment with the drug. The inset shows the mean $\pm 95 \%$ confidence $(n=10$ for $1 \times \mathrm{MBC}$ and $n=20$ for other concentrations). A full color version of this figure is available at The Journal of Antibiotics journal online.

with $0.5 \mu \mathrm{g} \mathrm{ml}^{-1}$ were significantly wider than the control (Figure 3a). At concentrations of $\mathbf{1 0}>0.5 \mathrm{~g} \mathrm{~m} \mathrm{ml}^{-1}$, there was a gradual but significant reduction in the size of the bacteria. Moreover, untreated $S$. aureus showed a round and firm geometry with distinct surface features, which become distorted with increasing drug concentrations. Atomic force microscopy (AFM) also revealed a statistically significant change in morphology of the uppermost $25 \mathrm{~nm}$ region of $S$. aureus (see Figure $3 \mathrm{~b}$ for illustration). This region 


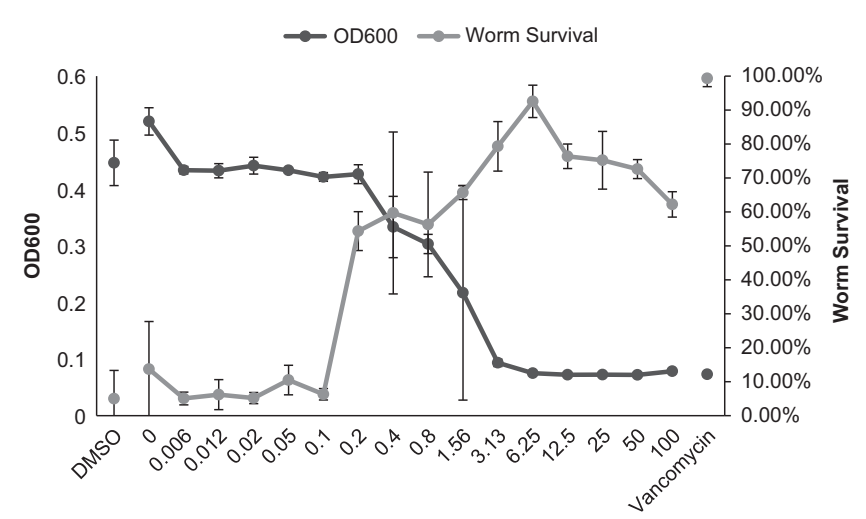

Figure 4 Percentage of surviving $C$. elegans as a function of 10 concentration and density of surviving bacteria as a function of 10 concentration in the absence of $C$. elegans. The percentage of worm survival is shown in red with the corresponding axis on the right and the growth of MRSA MW2 is shown in blue with the corresponding axis on the left. Concentrations are shown in $\mu \mathrm{g} \mathrm{ml}^{-1}$. The negative control with solvent DMSO is shown on the far left and the positive control with antibiotic vancomycin is shown on the far right. A full color version of this figure is available at The Journal of Antibiotics journal online.

was observed to be of narrow parabolic geometry in the control sample, which then flattened as the drug concentration increased (Figure $3 \mathrm{~b}$ ). The AFM and SEM results support each other, as the latter width measurement is inversely proportional to the measurement of the parabolic curvature parameter ' $a$ '. These morphological changes are consistent with the spontaneous activation of MscL in the presence of $\mathbf{1 0}$ leading to solute loss and osmolytes and consequently a reduction in the size of $S$. aureus.

Compound 10 is effective in an animal model of $S$. aureus infection Compound $\mathbf{1 0}$ has potent antibacterial activity in vitro, and accordingly we tested whether this activity would translate to in vivo models of infection. We examined the efficacy of $\mathbf{1 0}$ in treating the nematode C. elegans infected with MRSA strain MW2. Approximately $60 \%$ of the worms survived when treated with $\mathbf{1 0}$ at concentrations above 0.2 $\mu \mathrm{g} \mathrm{ml}^{-1}$ and $>90 \%$ of the worms survived the MRSA infection at the most effective concentration of $10,6.25 \mu \mathrm{g} \mathrm{ml}^{-1}$ compared with a $5 \%$ survival rate for the control (Figure 4). The range of effective concentrations $\left(0.2-100 \mu \mathrm{g} \mathrm{ml}^{-1}\right)$ also corresponded to low bacterial counts in vitro as detected by measuring the $\mathrm{OD}$ at $600 \mathrm{~nm}\left(\mathrm{OD}_{600}\right)$ in assay wells without the presence of worms.

\section{DISCUSSION}

Compound $\mathbf{1 0}$ is a potent antibiotic against drug-resistant Gram-positive bacteria with limited activity against Gram-negative species. However, it is worth noting that although $\mathbf{1 0}$ showed no apparent effect on E. coli ATCC $25922\left(\mathrm{MIC}>64 \mu \mathrm{g} \mathrm{ml}^{-1}\right)$, it did show an inhibitory effect on the growth of E. coli MJF612 ( $\mathrm{MIC} \sim 13.5 \mu \mathrm{g} \mathrm{ml}^{-1}$ ) as shown in Figures $2 \mathrm{a}$ and $\mathrm{b}$. The difference in effect is due to a strain variation, being previously observed for a number of fluoroquinolone antibiotics where in some cases the difference in susceptibility between the WT and the ATCC 25822 strains was over fourfolds. ${ }^{22}$ The reduced activity against Gram-negative bacteria presumably arises from the presence of the lipopolysaccharide-containing outer membrane, which acts as a barrier to hydrophobic compounds such as $\mathbf{1 0}$. Although 10 kills bacteria, it is nontoxic to mammalian cells. The lowest concentration at which any cytotoxicity has been observed in any cell line is 50 $\mu \mathrm{g} \mathrm{ml}^{-1}$, allowing for a tolerated therapeutic window between 4 and $50 \mu \mathrm{g} \mathrm{ml}^{-1}$ for MRSA.

We have shown here that, the potency of the antimicrobial activity of $\mathbf{1 0}$ is dependent on MscL. These data are consistent with the in silico results, suggesting binding of the compound to the channel. 10 represents the first success at designing a drug with specificity to MscL. Some previous studies suggest that there are other antibacterial compounds that may have some influence on the channel; however, most of these studies did not show both an in vivo dependence upon MscL expression and a direct effect on channel activity. The bacterial toxin sublancin $168,{ }^{23}$ a glucosylated bacteriocin showed MscLdependent activity against Bacillus subtilis and $S$. aureus in vivo, but there was no assessment of the role of MscS or any electrophysiological studies. Another group of antimicrobial agents (Parabens) has been reported to affect MscL as assayed by patch-clamp analysis, but there have been no in vivo studies to determine any MscL-dependent effects. Parabens affect MscS as well as MscL, ${ }^{24,25}$ suggesting that they are nonspecific activators of membrane-tension-gated channels, as has been observed for several amphipaths. ${ }^{26,27}$ Finally, MscL expression has recently been shown to increase streptomycin potency, and overall the effects appear to be specific for MscL, suggesting direct binding; the open channel may even serve as a route for streptomycin to get access to the cytoplasm. ${ }^{21} 10$ affects MscS- as well as MscL-expressing cells, suggesting it might have some amphipathic or nonspecific ability to activate bacterial membrane-tension-gated channels in vivo. However, in patch-clamp experiments, only MscL showed a decrease in the pressure threshold in the presence of 10, in agreement with a facilitation to gate MscL. Hence, the predicted binding of 10 to MscL and the finding that MscL appears to be more affected than $\mathrm{MscS}$ as assayed by patch-clamp suggests that while there may be an amphipathic component to MscL activation by 10 in vivo, there may also be a more MscL-specific agonist action as well. In addition, the flow cytometry experiments show that there is no compromise to the integrity of the plasma membrane, consistent with the interpretation that $\mathbf{1 0}$ directly interacts with the channels. At last, microscopic imaging using SEM and AFM analysis reveal a significant change in bacterial cell morphology in bacteria treated with 10, with the bacteria flattened and shrunk, which is consistent with MscL channel activation. Therefore, these data suggest that MscL is a target for $\mathbf{1 0 .}$

In vivo testing of $\mathbf{1 0}$ in an MRSA infection model in the nematode C. elegans has shown that the drug is an active antibiotic, rescuing the worms from the infection at a concentration of $\sim 1.5 \mu \mathrm{g} \mathrm{ml}^{-1}$ (Figure 4). The worm infection model represents a therapeutic window from 0.2 to $50 \mu \mathrm{g} \mathrm{ml}^{-1}$, a range at which no toxicity is observed in human cell lines. This therapeutic window is better than that of FDA-approved antibiotics, such as tobramycin and gentamicin (therapeutic range of 4-10 $\mu \mathrm{g} \mathrm{ml}^{-1}$ ), amikacin (therapeutic range 20$30 \mu \mathrm{g} \mathrm{ml}^{-1}$ ) and vancomycin (therapeutic range $20-40 \mu \mathrm{g} \mathrm{ml}^{-1}$ ). The results highlight and address some of the preliminary challenges in antibiotic development and pave the way for future research and development for the antimicrobial compounds discussed herein, including resistance emergence testing, formulation of $\mathbf{1 0}$ and analogs thereof, in addition to investigating different routes of administration using different animal infection models.

\section{METHODS}

\section{In silico design experiments}

Autodock $3.05^{28}$ was used for the in silico docking experiments as it is well documented and has a graphical user interface (Autodocktools) that is simple 
to use. The atomic coordinates of the MscL protein from E. coli were obtained from a homology structure designed previously. ${ }^{29}$ In this structure, the aminoacid residues of $M$. tuberculosis have been replaced with those of $E$. coli and the coordinates of the amino acids left unaltered. The Eco MscL structure used is a truncated version of MscL and has only 95 amino-acid residues (Met12 to Glu107), compared with the 136 amino-acid residues representing the whole protein. Past experiments suggest that the rest of the protein is not significant for the activity of MscL and therefore removing it was advantageous by saving computer power and significantly reducing the computational time. The Protein Data Bank file of the Eco MscL was loaded in Autodocktools and the water molecules removed. Polar hydrogens were added to the proteins and the charges and solvation parameters were added to the atoms of the macromolecule, and the file saved in Protein Data Bank file format with charges and solvation parameters included.

The ligands were built and saved in Brookhaven format ${ }^{30}$ and Autodocktools was used to prepare the ligands for docking. The rigid root of the ligand was defined automatically and the maximum number of rotatable bonds was allowed. The number of active torsions was set to the number of rotatable bonds and the toggle activity of torsions allowed to move most atoms. The partial atomic charges were calculated ${ }^{31}$ using the AM1 Hamiltonian, and the geometry of the ligand was optimized. These were entered into the Protein Data Bank file replacing the charges generated using Autodocktools.

The grid size and center used for the Autodock calculation (see Supplementary Table S1 for parameters used for docking) was restricted to the amino-acid residues near Ala20, as it has been shown that this is where parabens and eriochrome cyanine bind. ${ }^{24}$ To narrow down the search for target amino acids, the amino acids that surround the docked ligands were determined. The amino-acid residues surrounding the ligands for most of the dockings ranged from Leu19 to Lys31. Hydrogen acceptor groups (namely oxygen atoms) were targeted in the protein side chain. Depending on where they occur, a ligand with hydrogen donor groups was then designed that can $\mathrm{H}$-bond with the oxygen atoms. This approach was taken given that there were a limited number of amino acids with oxygen atoms exposed to the inside of the pore. This identified amino acids, Leu19, Ala20, Val23, Gly26 and Ala27, with oxygen atoms exposed to the inside of the pore. The oxygen atoms in Gly26 and Ala27 are slightly shielded by other amino acids. In addition, they point to the side rather than to the inside of the pore, and hence may not contribute significantly to hydrogen bonding.

It is also important to note that the geometry of these five amino acids is the same in the five subunits, as long as no more than one amino acid is considered to be in any subunit. Therefore, instead of visualizing these amino acids in one chain, they were visualized as an amino acid/subunit so that subunit 1 has Leu19, subunit 2 has Ala20, subunit 3 has Val23, subunit 4 has Gly26 and subunit 5 has Ala27.

As parts of the protein pore are narrower than others, it was important to design a pharmacophore that has a length less than the diameter of the pore at the position of all five amino-acid residues. If this is the case, then any one pharmacophore will, at most, bind to four amino acids. Owing to the fact that the most accessible oxygen atoms are in the following amino acids: Leu19, $\mathrm{Ala} 20$ and Val23, particular attention was given to these amino acids.

A de novo approach was undertaken to design a pharmacophore and seven ligands were constructed with three hydroxyl groups each (Figure 1a). These ligands were then docked with the Eco MscL. The assumption being that the closer the hydroxyl groups of a ligand to the spatial dimensions of the ketone groups in Eco MscL (Supplementary Table S2), the better the docking. This was not the case; nonetheless, the results showed exceptional docking energies for ligand 2, which was then used as a lead in an iterative docking process.

The hydroxyl groups in ligand 2 were replaced by various functional groups and the effect on docking energy was noted. The functional groups include: aldehydes, amide cations, amino, carboxyl and chlorines (Figure 1c). The carboxyl groups were deprotonated and were added, one at a time, until the carboxyl groups replaced all the hydroxyl groups. The four phenyl groups of ligand 2 were also replaced by cyclohexane groups. The parent compound was also included (which did not include the hydroxyl groups).

The best docking energy was observed with replacement of all hydroxyl groups for carboxyl groups with an overall charge of -3 on the molecule.
This ligand has an exceptional free energy of binding equivalent to $\sim-55.94$ $\mathrm{kJ} \mathrm{mol}^{-1}$, which is higher than that previously reported. ${ }^{6} \mathrm{MscL}$ may not show an overall ion selectivity; however, the docking results show preferential binding to the mostly hydrophobic deprotonated tri-acid species.

\section{Compound 10 synthesis}

Drug synthesis was carried out using a procedure published previously ${ }^{32}$ with some modifications. Ethyl acetate $(20 \%)$ in hexane was used for monitoring the progress of the Heck cross-coupling reaction using thin layer chromatography and 20:80 ethyl acetate-dichloromethane for eluting the product using fine silica after tetrahydrofuran removal under vacuum. The product from the saponification reaction was collected by filtration and eluted in fine silica using a 20:80 methanol-tetrahydrofuran solvent system, followed by the addition of diethyl ether as an anti-solvent to wash the compound.

\section{MIC assay}

All compounds were prepared at $160 \mu \mathrm{g} \mathrm{ml}^{-1}$ in water from a stock solution of $20 \mathrm{~mm}$ of 10 in dimethyl sulfoxide (DMSO). The compounds, along with standard antibiotics, were serially diluted twofold using Mueller Hinton broth (MHB) in 96-well plates (nonbinding surface, Corning 3641, Tewksbury, MA, USA) using MHB. Concentrations of standards ranged from $64 \mu \mathrm{g} \mathrm{ml}^{-1}$ to $0.03 \mu \mathrm{g} \mathrm{ml}^{-1}$, and concentrations of compounds ranged from 8 to 0.003 $\mu \mathrm{g} \mathrm{ml}{ }^{-1}$, with final volumes of $50 \mu \mathrm{l}$ per well. Gram-positive bacteria were cultured in MHB (Bacto Laboratories Pty Ltd, Mt Pritchard, NSW, Australia) at $37^{\circ} \mathrm{C}$ overnight. Mid-log phase bacterial cultures were diluted to the final concentration of $5 \times 10^{5} \mathrm{CFU} \mathrm{ml}^{-1}$ (in $\mathrm{MHB}$ ) and used with the diluted compounds to be tested. Plates were covered and incubated at $37^{\circ} \mathrm{C}$ for $24 \mathrm{~h}$, and MICs designated as the lowest concentration that showed no visible growth. Experiments were carried out in duplicate $(n=2)$, with vancomycin as a positive inhibitor control.

\section{M. tuberculosis testing}

Rifampicin and 10 were resuspended in DMSO and diluted to obtain a drug concentration of $160 \mu \mathrm{g} \mathrm{ml}^{-1}$. Five microliter of this drug concentration (equivalent to $0.8 \mu \mathrm{g}$ ) was dispensed into a 96-well plate and serially twofold diluted in DMSO (final drug volume $5 \mu \mathrm{l}$ ). Thereafter, frozen aliquots of the bacterial strains H37Rv and Victor strain TT372 were thawed and suspended at $2 \times 10^{5}$ bacteria per $\mathrm{ml}$ in $7 \mathrm{H} 9$ media supplemented with oleic acid, albumin, dextrose and catalases (final albumin concentration of $5 \mathrm{gl}^{-1}$ ). Two hundred microliter of these bacterial suspensions were added to each well in 96-well plates, containing either compound (final drug concentration: $4 \mu \mathrm{g} \mathrm{ml}^{-1}$ ). Plates were incubated at $37^{\circ} \mathrm{C}$ for 7 days, when $20 \mu \mathrm{l}$ of Alamar Blue reagent were added to each well. Plates were incubated for an additional 2 days at $37^{\circ} \mathrm{C}$, when absorbance was evaluated in a microtiter plate reader at $570 \mathrm{~nm}$. Bacterial absorbance was normalized to the blank absorbance and compared with the positive control (untreated bacteria). Data were graphed as percent inhibition. A similar procedure was carried out for M. tuberculosis $\mathrm{H} 37 \mathrm{Rv}$ grown in glycerol-alanine-salts medium and Proskauer and Beck medium at a pH 7.4. At concentration $\geqslant 80 \mathrm{\mu g} \mathrm{ml}^{-1}, 10$ precipitated in glycerol-alanine-salts medium $\mathrm{pH}$ 6.6. However, no precipitation was observed at lower concentrations (40$5 \mu \mathrm{g} \mathrm{ml}^{-1}$ ) where it also inhibited bacterial growth.

\section{NIH/3T3 and HaCaT cytotoxicity assay}

$\mathrm{HaCaT}$ immortalized keratinocytes and NIH/3T3 fibroblasts were seeded as $1.5 \times 10^{3}$ cells per well in a 96-well plate in $50 \mu \mathrm{l}$ media (Dulbecco's modified Eagle's medium/F12+GlutaMAX from Gibco (Mulgrave, VIC, Australia) with $10 \% \mathrm{v} / \mathrm{v}$ foetal bovine serum and $1 \% \mathrm{v} / \mathrm{v}$ penicillin/streptomycin). Cells were incubated for $2 \mathrm{~h}$ at $37^{\circ} \mathrm{C}, 5 \% \mathrm{CO}_{2}$ to allow cells to attach to the plates. 10 was prepared in DMSO and diluted 20 times in culture media, giving a final concentration of $1 \mathrm{mg} \mathrm{ml}^{-1}$ with 5\% DMSO. Fifty microliter of each dilution was added into $50 \mu \mathrm{l}$ of culture medium in triplicates to reach the final concentrations. The cells were incubated with the compounds overnight at $37^{\circ} \mathrm{C}, 5 \% \mathrm{CO}_{2}$. After the incubation, MTS(3-(4,5-dimethylthiazol-2-yl)-5(3-carboxymethoxyphenyl)-2-(4-sulfophenyl)-2H-tetrazolium, inner salt) (Promega, Australia, Alexandria, NSW, Australia) $(60 \mu \mathrm{l})$ was added to each well. The plates were then incubated for $3 \mathrm{~h}$ at $37^{\circ} \mathrm{C}, 5 \% \mathrm{CO}_{2}$. Sixty microliter 
from each well was transferred to a new plate and the absorbance was then read at $490 \mathrm{~nm}$ using EnSpire 2300 Multimode Plate Reader. Results are presented as the average percentage of control \pm s.d. for each set of duplicate wells. The difference between the experiment and the blank is recorded as normalized mean. For each treatment, the experiment was carried out in triplicate for each time point, at $0,24,48$ and $72 \mathrm{~h}$. Time 0 starts after overnight incubation.

\section{HepG2 and HEK293 cytotoxicity assay}

10 was prepared in DMSO at $20 \mathrm{~mm}$. It was diluted 200 times in culture media, giving a final concentration of $50 \mu \mathrm{g} \mathrm{ml}^{-1}$ with $0.5 \%$ DMSO. Hepatocellular carcinoma (HepG2 ATCC HB-8065) and human embryonic kidney cells (HEK293 ATCC CRL-1573) cells were seeded as $1.5 \times 10^{4}$ cells per well in a 96-well plate in a final volume of $100 \mu$ in Dulbecco's modified Eagle's medi (Gibco-Invitrogen, Waltham, MA, USA), in which $10 \%$ or $1 \%$ of foetal bovine serum was added. Cells were incubated for $24 \mathrm{~h}$ at $37^{\circ} \mathrm{C}, 5 \% \mathrm{CO}_{2}$ to allow cells to attach. All tested compounds were diluted from $2.5 \mathrm{mg} \mathrm{ml}^{-1}$ to $0.38 \mu \mathrm{g} \mathrm{ml}^{-1}$ in threefold dilutions. Then, $10 \mu \mathrm{l}$ of each dilution was added into $90 \mu \mathrm{l}$ of culture medium in triplicates. Colistin and Tamoxifen were used as the controls. The cells were incubated with the compounds for $24 \mathrm{~h}$ at $37^{\circ} \mathrm{C}, 5 \% \mathrm{CO}_{2}$. After the incubation, 3-(4,5-Dimethylthiazol-2-yl)-2,5-diphenyltetrazolium bromide (Invitrogen) was added to each well to a final concentration of $0.4 \mathrm{mg} \mathrm{ml}^{-1}$. The plates were then incubated for $2 \mathrm{~h}$ at $37^{\circ} \mathrm{C}, 5 \% \mathrm{CO}_{2}$. Medium was removed, and crystals were resuspended in $60 \mu \mathrm{l}$ of DMSO. The absorbance was then read at $570 \mathrm{~nm}$ using a Polarstar Omega instrument. The data were then analyzed by Prism software. Results are presented as the average percentage of control \pm s.d. for each set of duplicate wells using the following equation: Percent viability = $\left(\mathrm{ABS}_{\mathrm{TEST}}-\mathrm{ABS}_{5 \% \mathrm{DMSO}} / \mathrm{ABS}_{\text {UNTREATED }}-\mathrm{ABS}_{5 \% \mathrm{DMSO}}\right) \times 100$.

\section{Strains and cell growth}

Constructs were inserted in the PB10d expression vector ${ }^{9,33-35}$ and the E. coli strain MJF612, which is null for MscL, MscS and MscS homologs (FRAG-1 $\Delta m s c L:: c m, \Delta m s c S, \Delta m s c K:: k a n, \Delta y b d G:: a p r \Delta)^{17}$ were used as a host for all experiments. Unless stated otherwise, cells were grown in citrate-phosphate defined medium consisting of (per liter: $8.57 \mathrm{~g}$ of $\mathrm{Na}_{2} \mathrm{HPO}_{4}, 0.87 \mathrm{~g}$ of $\mathrm{K}_{2} \mathrm{HPO}_{4}$, $1.34 \mathrm{~g}$ of citric acid, $1.0 \mathrm{~g}$ of $\mathrm{NH}_{4} \mathrm{SO}_{4}, 0.001 \mathrm{~g}$ of thiamine, $0.1 \mathrm{~g}$ of $\mathrm{Mg}_{2} \mathrm{SO}_{4} \cdot 7 \mathrm{H}_{2} \mathrm{O}, \quad 0.002 \mathrm{~g}$ of $\left.\left(\mathrm{NH}_{4}\right)_{2} \mathrm{SO}_{4} \cdot \mathrm{FeSO}_{4} \cdot 6 \mathrm{H}_{2} \mathrm{O}\right)$ plus $100 \mu \mathrm{g} \mathrm{ml}{ }^{-1}$ ampicillin.

\section{In vivo growth inhibition experiments}

E. coli strain MJF612 was used as a host for Eco MscL (MscL), K55T Eco MscL (K55T MscL), C. perfringens MscL, SA MscL and E.coli MscS (MscS) constructs in the PB10d expression vector. Overnight cultures were grown in citratephosphate defined medium $\mathrm{pH} 8$ plus $100 \mu \mathrm{g} \mathrm{ml}^{-1}$ ampicillin with shaking at $37^{\circ} \mathrm{C}$. The following day, cultures were diluted 1:40 in the same media and grown for $30 \mathrm{~min}$ before inducing expression with $1 \mathrm{~mm}$ isopropyl $\beta$-D-1thiogalactopyranoside. After $30 \mathrm{~min}$ of induction, all cultures were adjusted to an $\mathrm{OD}_{600}$ of 0.08 . The cultures were then diluted 1:3 into pre-warmed citratephosphate defined medium $\mathrm{pH} 8$ containing $100 \mu \mathrm{g} \mathrm{ml}^{-1}$ ampicillin plus $\mathbf{1 0}$. Cultures were loaded in 96-well plates $(190 \mu \mathrm{l}$ per well), sealed with a breathable film, and incubated at $37^{\circ} \mathrm{C}$ for $16 \mathrm{~h}$ without shaking. The $\mathrm{OD}_{595}$ of the cultures was measured using a Multiskan Ascent (Thermo Scientific Inc., Waltham, MA, USA).

\section{Electrophysiology}

E. coli giant spheroplasts were generated as previously described ${ }^{20}$ from PB104 strain $(\Delta m s c L:: C m)^{34}$ expressing Eco MscL. Patch-clamp experiments were performed in the inside-out configuration, at room temperature under symmetrical conditions in a buffer at pH $6.0\left(200 \mathrm{~mm} \mathrm{KCl}, 90 \mathrm{~mm} \mathrm{MgCl}_{2}\right.$, $10 \mathrm{mM} \mathrm{CaCl}_{2}$ and $5 \mathrm{~mm}$ HEPES). Patches were excised, and recordings were performed at $20 \mathrm{mV}$ (for simplicity the patch traces openings are shown upward). Data were acquired at a sampling rate of $20 \mathrm{kHz}$ with $10 \mathrm{kHz}$ filtration using an AxoPatch 200B amplifier (Molecular Devices, Sunnyvale, CA, USA). A piezoelectric pressure transducer (World Precision Instruments, Sarasota, FL, USA) was used to measure the pressure throughout the experiments. After taking three separate pressure threshold measurements in regular patch buffer for control, a $25 \mu \mathrm{g} \mathrm{ml}^{-1}$ solution of $\mathbf{1 0}$ was perfused to the bath and channel sensitivity within the same patch was measured subsequently every $10 \mathrm{~min}$.

\section{Flow cytometry experiments}

Bacterial cultures were prepared from a single colony of E. coli FRAG-1 grown on Lysogeny Broth media. The single colony was added to $8.5 \mathrm{ml}$ of filtered MHB $\left(0.2 \mu \mathrm{M}\right.$ Minisart, Sartorius Stedim) to which $10\left(3.375 \mu \mathrm{g} \mathrm{ml}^{-1}\right.$ to 54 $\mu \mathrm{g} \mathrm{ml}^{-1}$ in doubling concentrations) was added. The cultures were incubated overnight at $37^{\circ} \mathrm{C}$ with shaking in $2 \mathrm{ml}$ volumes before analysis, at which point SYBR Green I $\left(10 \times\right.$ final in MHB) and PI $\left(10 \mu \mathrm{g} \mathrm{ml}^{-1}\right.$ final in $\left.\mathrm{H}_{2} \mathrm{O}\right)$ were added. Cells were incubated for $5 \mathrm{~min}$, prior to analysis. The heat-treated sample was exposed to $60^{\circ} \mathrm{C}$ for $20 \mathrm{~min}$ before adding SYBR Green I and PI and incubated for $5 \mathrm{~min}$.

An Accuri C6 Flow Cytometer was used for the flow cytometer experiments. The fluidics rate was set to Medium $\left(35 \mu \mathrm{min}^{-1}\right)$ and the threshold limit was set on FL1 (530/30) to a value of 800. Samples were run and 30000 events collected. Sample data were analyzed using the CFlow software. FL2-A (585/60) $\left(\mathrm{Em}_{\max } 605 \mathrm{~nm}, \mathrm{PI}\right)$ was plotted on the $y$ axis versus FL1-A (530/30) $\left(\mathrm{Em}_{\max }\right.$ $521 \mathrm{~nm}$, SYBR Green I) on the $x$ axis. No gates were applied and fluorescence compensation was not required.

\section{Sample preparation for microscopy}

The bacterial strain S. aureus ATCC 6538 was grown overnight at $37^{\circ} \mathrm{C}$ on Muller-Hinton Agar (Oxoid, Thermo Fisher Scientific Inc., Waltham, MA, USA). The bacteria were harvested and the OD of bacteria suspended in MHB was adjusted to $\sim 0.5 \mathrm{MacF}$ arlane units so as to give $5 \times 10^{7} \mathrm{CFU} \mathrm{ml}^{-1}$. Bacteria were then aliquoted into $10 \mathrm{ml}$ tubes and various amounts of 10 at $1 \mathrm{mg} \mathrm{ml}^{-1}$ dissolved in DMSO were added to give a final concentration ranging from $32 \mu \mathrm{g} \mathrm{ml}^{-1}$ to $0.5 \mu \mathrm{g} \mathrm{ml}^{-1}$ (twofold serial dilutions). Bacterial numbers were enumerated using the Miles-Misra method in which serial dilutions of $10 \mu \mathrm{l}$ samples from each culture were spread onto nutrient agar in duplicate. After incubation at $37^{\circ} \mathrm{C}$ for $24 \mathrm{~h}$, the colonies were counted.

S. aureus ATCC 6538 cultures were treated as above and incubated overnight. Cultures were loaded into sterile disposable syringes and filtered through a $0.2-\mu \mathrm{m}$ isopore polycarbonate hydrophilic filter (Millipore, Billerica, MA, USA). Bacteria on filters were fixed in $4 \%$ paraformaldehyde $/ 1.25 \%$ glutaraldehyde in phosphate-buffered saline and $4 \%$ sucrose $(\mathrm{pH}$ 7.2) for $15 \mathrm{~min}$. The fixative was removed with a sterile pipette and the filters washed in a washing buffer composed of $4 \%$ sucrose in phosphate-buffered saline for $5 \mathrm{~min}$. The washing buffer was then removed and the bacteria were post-fixed in $2 \% \mathrm{OsO}_{4}$ in water for $30 \mathrm{~min}$. The $\mathrm{OsO}_{4}$ were then pipetted out into an osmium waste bottle and the bacteria were washed in a washing buffer composed of $4 \%$ sucrose in phosphate-buffered saline for $5 \mathrm{~min}$. The bacteria were then dehydrated in four consecutive different concentrations of ethanol, $70 \%$ ethanol ( 1 change of $10 \mathrm{~min}$ ), $90 \%$ ethanol (1 change of $10 \mathrm{~min}$ ), $95 \%$ ethanol ( 1 change of $10 \mathrm{~min}$ ) and $100 \%$ ethanol ( 3 changes of $10 \mathrm{~min}$ ). After removing the ethanol, the bacteria were critical point dried in hexamethyldisilazane ( 2 changes of $15 \mathrm{~min}$ ) and then mounted on a stub and platinum coated $(10 \mathrm{~nm})$. Carbon paint was then applied to the edges of the stub making contact with the filter to improve conductivity and reduce sample charging.

\section{Scanning electron microscopy analysis}

SEM was carried out using a FEG Quanta 450 microscope at an accelerating voltage of 3-7 Kv and a working distance of $10 \mathrm{~mm}$. The specimens were observed using a secondary electron detector under high-vacuum conditions. Images were captured at high definition at $\sim \times 85000$ magnification and a scan rate of $100 \mathrm{~ms}$ per frame.

\section{Atomic force microscopy analysis}

AFM images were acquired in air using a Bruker Dimension FastScan AFM with a Nanoscope V controller, operating in PeakForce Tapping mode. Bruker ScanAsyst Air probes with a nominal tip radius of $2 \mathrm{~nm}$ and nominal spring constant of $0.4 \mathrm{~N} \mathrm{~m}^{-1}$ were used. Imaging parameters including set-point, scan rate $(1-2 \mathrm{~Hz})$ and feedback gains were adjusted to optimize image quality and minimize imaging force. Images were analyzed using the Bruker Nanoscope Analysis software (version 1.4). The AFM scanner was calibrated in the $\mathrm{x}, \mathrm{y}$ and 
$\mathrm{z}$ directions using silicon calibration grids (Bruker model numbers PG: $1 \mu \mathrm{m}$ pitch, $110 \mathrm{~nm}$ depth and VGRP: $10 \mu \mathrm{m}$ pitch, $180 \mathrm{~nm}$ depth).

After acquiring the images, 20 bacteria per sample were chosen at random and a cross-section was drawn through the apex of each bacteria. The shape of the uppermost $25 \mathrm{~nm}$ of each bacteria was analyzed by fitting the parabolic function $y=\mathrm{ax}^{2}+\mathrm{bx}+\mathrm{c}$, and extracting the coefficient ' $\mathrm{a}$ ', which represents the curvature of the parabola. Higher 'a' values describe a narrow apex geometry, whereas low 'a' values describe a flatter apex with lower curvature. The analysis was restricted to the uppermost $25 \mathrm{~nm}$ in order to ensure that all of the samples were analyzed in the same manner, as many of the bacteria are embedded in organic matter to varying degrees, which restricts the analysis region in each case.

\section{C. elegans infection model}

The C. elegans infection assay was carried out as previously described. ${ }^{36} \mathrm{~A}$ stock solution of $\mathbf{1 0}$ in DMSO $\left(10 \mathrm{mg} \mathrm{ml}^{-1}\right)$ was prepared. Dilution series consisting of 1:10 dilution (from $100 \mu \mathrm{g} \mathrm{ml}^{-1}$ ) and a 1:2 dilution (from $100 \mu \mathrm{g} \mathrm{ml}^{-1}$ ) were tested. To prepare a 1:10 dilution series, $5 \mu \mathrm{l}$ of $100 \mu \mathrm{g} \mathrm{ml}^{-1}$ of 10 was diluted into $45 \mu \mathrm{l}$ of liquid media with $1 \%$ DMSO. This was repeated for all dilutions. To each well, $20 \mu \mathrm{l}$ of compound containing liquid media was added followed by the addition of $35 \mu \mathrm{l}$ of MRSA and $15 \mu \mathrm{l}$ media containing 15 worms. Vancomycin at 20 and $100 \mu \mathrm{g} \mathrm{ml}^{-1}$ were used as positive controls and DMSO was used as a negative control. After infection and co-incubation with compound for 4 days, bacteria were washed out and the worms were stained with Sytox Orange dye and imaged. The ratio of stained to unstained worm area was used to measure worm death. Prior to washing, an $\mathrm{OD}_{600}$ measurement was taken to assess the bacterial growth.

Full methods and any associated references are available in the online version of the paper at www.nature.com/nature.

\section{CONFLICT OF INTEREST}

$\mathrm{RAB}$ declares ownership of the intellectual property licensed to Boulos \& Cooper Pharmaceuticals Pty Ltd. The remaining authors declare no conflict of interest.

\section{ACKNOWLEDGEMENTS}

The in vivo growth inhibition experiments and the electrophysiology experiments were supported by Grant I-1420 of the Welch Foundation, Grant RP100146 from the Cancer Prevention \& Research Institute of Texas, and Grants AI08080701 and GM061028 from the National Institutes of Health. The C. elegans experiments were supported by grant P01 AI083214 from the National Institutes of Health. II is supported by Grant 12SDG8740012 from the National American Heart Association. The funding bodies had no role in study design, data collection and analysis, decision to publish or preparation of the manuscript. The content is solely the responsibility of the authors and does not necessarily represent the official views of the National Institutes of Health. MAB, JXH, SR and AK were supported by a Wellcome Trust Seeding Drug Discovery Award (094977/Z/10/Z), and MAC by an NHMRC Principal Research Fellowship (APP1059354). UHS is supported by NHMRC Project Grant 535053. We gratefully acknowledge support of this work by the Australian Research Council and the Government of South Australia. RAB gratefully acknowledges supervision from Allan J McKinley during his Honors year when the modeling work was undertaken. SEM analysis was carried out at Adelaide Microscopy and AFM studies were carried out using facilities in the School of Chemical and Physical Sciences, Flinders University. Both of these microscopy facilities are supported by the Australian Microscopy and Microanalysis Research Facility (AMMRF). Flow Cytometry experiments were carried out at Flow Cytometry Immunology facility at Flinders Medical Centre. Ramizol is a Trademark fully registered in Australia.

Author contributions: RW and II conducted the in vivo growth inhibition studies and the electrophysiology, $\mathrm{JlF}$ and $\mathrm{AlC}$ carried out the C. elegans infection work, SR, AK and JXH conducted the susceptibility testing of MDR $S$. aureus and S. pneumonia, and cytotoxicity of HEK293 and HepG2 cells, AO carried out the susceptibility testing of $M$. tuberculosis, EST carried out the cytotoxicity studies on $\mathrm{NIH} / 3 \mathrm{~T} 3$ and $\mathrm{HaCaT}$ cells lines, UHS conducted experiments on the effect of $\mathbf{1 0}$ on viable counts of $S$. aureus and supplied cultures for microscopy, NVH carried out the flow cytometry experiments, $\mathrm{RAB}$ carried out the in-silico studies, synthesis of $\mathbf{1 0}$ and prepared the samples for microscopy, $\mathrm{ClT}$ and $\mathrm{RAB}$ carried out the scanning electron microscopy analysis, $\mathrm{ADS}$, CTG and RAB carried out the atomic force microscopy analysis, II, PB, AIC, JLF, FMA, MAB, UHS, MHB, AO, CLR and RAB wrote the manuscript, $\mathrm{PB}, \mathrm{FMA}, \mathrm{IO}, \mathrm{MHB}, \mathrm{MAC}, \mathrm{NVH}, \mathrm{CM}$ and $\mathrm{RAB}$ designed the experiments, and RAB coordinated the research.

1 Katz, M. L., Mueller, L. V., Polyakov, M. \& Weinstock, S. F. Where have all the antibiotic patents gone? Nat. Biotechnol. 24, 1529-1531 (2006).

2 Christoffersen, R. E. Antibiotics - an investment worth making? Nat. Biotechnol. 24, 1512-1514 (2006).

3 Clardy, J., Fischbach, M. A. \& Walsh, C. T. New antibiotics from bacterial natural products. Nat. Biotechnol. 24, 1541-1550 (2006).

4 Prasad, S. \& Smith, P. Meeting the threat of antibiotic resistance: building a new frontline defence. Australian Government Office of the Chief Scientist. http:// www.chiefscientist.gov.au/wp-content/uploads/OPS7-antibioticsPRINT.pdf (2013).

5 Piddock, L. J. Antibiotic action: helping deliver acation plans and strategies. Lancet Infect. Dis. 13, 1009-1011 (2013).

6 Butler, M. S. \& Cooper, M. A. Antibiotics in the clinical pipeline in 2011. J. Antibiot. 64, 413-425 (2011).

7 Barh, D. et al. A novel comparative genomics analysis for common drug and vaccine targets in Corynebacterium pseudotuberculosis and other CMN group of human pathogens. Chem. Biol. Drug. Des. 78, 73-84 (2011).

8 Boulos, R. A. Antimicrobial dyes and mechanosensitive channels. A. Van Leeuwenhoek 104, 155-167 (2013).

9 Prole, D. L. \& Taylor, C. W. Identification and analysis of putative homologues of mechanosensitive channels in pathogenic protozoa. PLoS One 8, doi:10.1371/journal. pone.0066068 (2013).

10 Corry, B. et al. An improved open-channel structure of MscL determined from FRET confocal microscopy and simulation. J. Gen. Physiol. 136, 483-494 (2010).

11 Wang, Y. et al. Single molecule FRET reveals pore size and opening mechanism of a mechano-sensitive ion channel. eLife 3, doi:10.7554/eLife.01834 (2014).

12 McKinley, A. J., Riley, T. V., Lengkeek, N. A., Stewart, S. G. \& Boulos, R. A. Antimicrobial Compounds. US20120329871 A1 (2012).

13 James, E. et al. A novel antimicrobial reduces oxidative stress in cells. RSC Adv. $\mathbf{3}$, 7277-7281 (2013).

14 DeGrado, W. F. \& Summa, C. M. De novo design and structural characterization of proteins and metalloproteins. Annu. Rev. Biochem. 68, 779-819 (1999).

15 Boulos, R. A. et al. Inspiration from old dyes: tris(stilbene) compounds as potent Grampositive antibacterial agents. Chem. Eur. J. 19, 17980-17988 (2013).

16 Quinlan, G. J., Martin, G. S. \& Evans, T. W. Albumin: biochemical properties and therapeutic potential. Hepatology 41, 1211-1219 (2005).

17 Schumann, U. et al. YbdG in Escherichia coli is a threshold-setting mechanosensitive channel with MscM activity. Proc. Natl Acad. Sci. 107, 12664-12669 (2010).

18 Yang, L. M., Zhong, D. \& Blount, P. Chimeras reveal a single lipid-interface residue that controls MscL channel kinetics as well as mechanosensitivity. Cell. Rep. 3, 520-527 (2013)

19 Zhong, D. \& Blount, P. Phosphatidylinositol is crucial for the mechanosensitivity of Mycobacterium tuberculosis MscL. Biochemistry 52, 5415-5120 (2013).

20 Blount, P., Sukharev, S. I., Moe, P. C., Martinac, B. \& Kung, C. Mechanosensitive Channels of Bacteria, vol. 294, 458-482. Academic Press: San Diego, CA, USA, 1999.

21 Iscla, I., Wray, R., Wei, S., Posner, B. \& Blount, P. Streptomycin potency is dependent on MscL channel expression. Nat. Commun. 5, doi:10.1038/ncomms5891 (2014).

22 Schedletzky, H. Wiedemann, B. \& Heisig, P. The effect of moxifloxacin on its target topoisomerases from Escherichia coli and Staphylococcus aures. J. Antimicrob. Chemother. 43, 31-37 (1999).

23 Kouwen, T. R. et al. The large mechanosensitive channel MscL determines bacterial susceptibility to the bacteriocin sublancin 168. Antimicrob. Agents Chemother. 53, 4702-4711 (2009).

24 Nguyen, T., Clare, B., Hool, L. C. \& Martinac, B. The effects of parabens on the mechanosensitive channels of E. coli. Eur. Biophys. J. 34, 389-395 (2005).

25 Kamaraju, K. \& Sukharev, S. I. The membrane lateral pressure-perturbing capacity of parabens and their effects on the mechanosensitive channel directly correlate with hydrophobicity. Biochemistry 47, 10540-10550 (2008).

26 Martinac, B., Adler, J. \& Kung, C. Mechanosensitive ion channels of E. coli activated by amphipaths. Nature 348, 261-263 (1990).

27 Perozo, E., Kloda, A., Cortes, D. M. \& Martinac, B. Physical principles underlying the transduction of bilayer deformation forces during the mechanosensitive channel gating. Nat. Struc. Mol. Biol. 9, 696-703 (2002).

28 Morris, G. M. et al. Automated docking using a Lamarckian genetic algorithm and an emperical binding free energy function. J. Comput. Chem. 19, 1639-1662 (1998).

29 Nguyen, T., Clare, B., Guo, W. \& Martinac, B. The effects of parabens on the mechanosensitive channels of E. coli. Eur. Biophys. J. 34, 389-395 (2005).

30 Spartan '02, Wavefunction, Inc.: Irvine, CA, USA, 2002.

31 Gaussian 98, Gaussian, Inc.: Pittsburgh, PA, USA, 1998

32 Lengkeek, N. A. et al. The synthesis of fluorescent DNA intercalator precursors through efficient multiple heck reactions. Aust. J. Chem. 64, 316-323 (2011). 
33 Moe, P. C., Levin, G. \& Blount, P. Correlating a protein structure with function of a bacterial mechanosensitive channel. J. Biol. Chem. 275, 31121-31127 (2000).

34 Blount, P., Sukharev, S. I., Schroeder, M. J., Nagle, S. K. \& Kung, C. Single residue substitution that change the gating properties of a mechanosensitive channel in Escherichia coli. Proc. Natl Acad. Sci. USA 93, 1652-11657 (1996).

35 Blount, P. et al. Membrane topology and multimeric structure of a mechanosensitive channel protein of Escherichia coli. EMBO J. 15, 4798-4805 (1996).

36 Rajamuthiah, R. et al. Whole animal automated platform for drug discovery against multi-drug resistant Staphylococcus aureus. PLOS ONE 9, doi:10.1371/journal. pone.0089189 (2014). (c) (1) () $\Theta$ This work is licensed under a Creative Commons Attribution-NonCommercial-NoDerivs 3.0 Unported License. The images or other third party material in this article are included in the article's Creative Commons license, unless indicated otherwise in the credit line; if the material is not included under the Creative Commons license, users will need to obtain permission from the license holder to reproduce the material. To view a copy of this license, visit http://creativecommons.org/licenses/by-nc-nd/3.0/

Supplementary Information accompanies the paper on The Journal of Antibiotics website (http://www.nature.com/ja) 